\title{
FUTURE CHALLENGES IN THE WAKE OF COVID-19 ON MENTAL HEALTH IN PAKISTAN- A SYSTEMATIC REVIEW
}

\author{
Seemi Tanvir ${ }^{\mathrm{a}}$, Mariam Babar ${ }^{\mathrm{b}}$, Ayesha Fazal $^{\mathrm{d}}$, Faiqa Fazal $^{\mathrm{d}}$ \\ ${ }^{a}$ Assistant Professor, Department of Pathology, Margalla Institute of Health Sciences. \\ 'Lecturer, Department of Pathology, Margalla Institute of Health Sciences. \\ ${ }^{\mathrm{d}}$ House officer, Department of Gynaecology, Fauji Foundation Hospital.
}

\begin{abstract}
:
BACKGROUND \& OBJECTIVE: Coronavirus disease (COVID-19) is a contagious disease that has shaken the mankind. Up till 30th June 2020, about 10.1 million people have been affected across 188 countries around the world. Deterioration of mental health is long-term effect of a pandemic. Methods for the control of COVID-19 have provoked fear, anxiety and frustration. Developed countries might be able to handle them but for a developing country it may prove an economic "Death Warrant". Pakistan is one of countries that have been fighting with COVID-19, with about $24 \%$ of the population living below the national poverty line and aftermaths of this pandemic still awaits. We intend to assess impact of COVID-19 on mental health in Pakistan to contribute towards the prevention of anticipated complications by getting a more clear picture.

METHODOLOGY: Online literature search was carried out from Jan 2020 to Jun 2020, using Google Scholar, Science Direct and PubMed with the help of key words. This resulted in retrieval of 151 articles after removing duplicated ones. Articles with incomplete information, case reports, case series, letters or editorials were also excluded. After shortlisting, seven articles were finally selected for the review.

RESULTS: This review observed that mental illnesses have been potentiated by COVID-19 due to its multi-dimensional manifestations especially on the economic growth of the country. Health care professionals and those having previous history of any psychological disabilities are the easy targets.
\end{abstract}

CONCLUSION: COVID-19 disease management and preventive measures to provide psychological support must go hand in hand.

KEYWORDS: Challenges, Coronavirus, Mental health, Future, Pakistan.

doi: https://doi.org/10.37723/jumdc.v12i1.478

\section{How to cite this:}

Tanvir S, Babar M, Afzal A, Fazal F. FUTURE CHALLENGES IN THE WAKE OF COVID-19 ON MENTAL HEALTH IN PAKISTAN- A SYSTEMATIC REVIEW. jumdc. 2021;12(1):51-58.

doi: https://doi.org/10.37723/jumdc.v12i1.478

This is an Open Access article distributed under the terms of the Creative Commons Attribution License (http://creativecommons.org/licenses/by/4.0), which permits unrestricted use, distribution, and reproduction in any medium, provided the original work is properly cited. 


\section{INTRODUCTION:}

Coronavirus disease (COVID-19) is a contagious disease that has shaken the mankind. Before the start of year 2020, nobody would have ever imagined that something not even visible with the naked eye would create havoc in this advanced era of scientific knowledge and research. Spread of Corona virus disease (COVID 19) proved that. It started off from vet markets in Wuhan (China) in December 2019. The situation escalated quickly, Up until now (June 2020), more than 10.1 million people have been effected across 188 countries and 502,000 have succumbed to the novel virus (Figure-I) ${ }^{[1]}$. In January, WHO declared it "PHEIC" (Public Health Emergency of International Concern) and has positioned it as $6^{\text {th }}$ under IHR (International Health Regulation $)^{[2] \text {. }}$

COVID 19 has proven to be one of the deadliest calamity of recent times. Its fatality rate is greater than influenza by $2.3 \%$ and more contagious than SARS ${ }^{[3]}$. All the affected countries are trying desperately to survive this pandemic including Pakistan. Every health emergency has serious repercussions as it affects people not only physically and economically but also mentally ${ }^{[4]}$. Same is the case with coronavirus infection. Now, as an established pandemic, COVID 19 has started to prove itself a major cause of mental health issues in the population ${ }^{[5]}$. Developing countries are coping with the disease desperately, by impeding movement of people completely, forcefully isolating them in the hope to curb the disease, because they are left with no choice but to put a halt to all kinds of activities ${ }^{[6]}$. On one hand, it has shown some improvement in slowing down the spread of this contagion but on the other hand, it has greatly affected the psychosocial wellbeing of people. This method of control has provoked a sense of fear, anxiety, frustration and uncertainty, sense of impending doom amongst the masses ${ }^{[7]}$.

Developed countries have the necessary resources to deal with such situations ${ }^{[6]}$, but for developing countries like Pakistan, where 24\% of the population already live below the national poverty line, these are inevitable pandemic aftershocks. ${ }^{[8]}$ As government has imposed

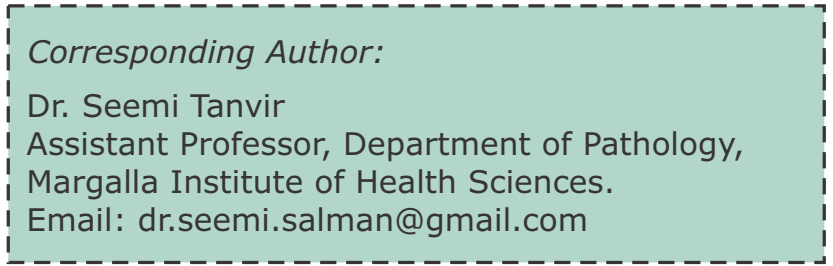

smart lock downs, recommended isolation and social distancing in order to contain and control coronavirus infection. These measures took a great toll on people from all walks of life ${ }^{[9]}$. Altered mental health cause huge damage in the form of disability burden of disease (FigureII) ${ }^{[10]}$.

Pakistan has significant prevalence of mental illnesses, COVID-19 proved "salt to the injury". With its dwindling economy, natural calamities, ever increasing population, Pakistan has already got its hands full ${ }^{[11]}$. In these testing times, proper financial aid as well as adequate resource management seems to be the key to success ${ }^{[5,12]}$. Stakeholders need to give their due attention to the seriousness of the nature of this disease, especially as there are some long term effects of the pandemic ${ }^{[13]}$. So, we planned our study in order to have a better understanding of the issue and capture the true essence of the condition at hand. In this way, the need for immediate measures can be assessed and allocation of the required resources can be done diligently. Mapping of the resources can be done accordingly, and people are dealt with equity, in order to reduce the severity of the aftermath. Mental health issue would prove to be one of the main health concerns of the officials, as already it is a recognized condition amongst the front line warriors (health workers). This study will provide some insight into this matter and prove its importance.

\section{METHODOLOGY:}

A detailed literature review, from January $1^{\text {st }}$, 2020 - June $30^{\text {th }}, 2020$, through online data bases like Google Scholar, Science Direct and PubMed was done. Key words like "Challenges", "Coronavirus", "Mental health" and other corresponding terms were used for searching. After searching all the search engines and removing records that were duplicated, 151 articles were retrieved. All articles related to

JUMDC Vol. 12, Issue 1, January-March 2021 
impact of covid-19 on mental health were included. Exclusion criteria included case series, case reports, letters and editorials. Hence, seven articles were selected for the review following the PRISMA 2009 criteria for the evidence based items which to assess the pros and cons for the health care intervention (Figure-III).

\section{RESULTS:}

As per the literature review, 7 articles were included in the studies which were following the inclusion criteria. Results deducted from the selected articles showed the impact of coronavirus pandemic on different population groups. Coronavirus disease has not affected all equally. The negative impact on mental health of the general public has caused development of depression which even worsen in people with pre-existing mental conditions ${ }^{[14]}$. The detailed study regarding women in this pandemic situations revealed a very unexpected and thought provoking aspect. They had to do all the households themselves (helpers or maids were stopped due to lock down). Less family members helped them. Most of them remained under stress due to their husbands' behaviors and unnecessary involvement in the house chores. Working ladies have to bear this more since they are not used to it as such ${ }^{[15]}$. This extraordinary situation affected students too but to a lesser extent. A web based survey on 500 students showed majority of the students were found to be normal $(65.9 \%)$, while $15.90 \%$ were found to be in severe depression associated with the COVID-19 situation ${ }^{[16]}$.

Health Care Workers (HCWs) are the frontline warriors in every pandemic but such situation do have their psychological effects on them. Levels of anxiety among them were $21.4 \%$ and $21.9 \%$ respectively and no statistically significant difference could be found between the HCWs of different disciplines ${ }^{[17]}$. However, significant difference was found between HCWs doing their duties in the COVID-19 ICU wards and that of isolation wards $(p=.020)$. Religious coping strategy was found to be most commonly adapted (5.98 \pm 1.73$)$, followed by

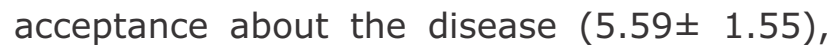
and then the coping planning (4.91 \pm 1.85$)$. Overall, anxiety and depression among the HCWs was found to be prevalent, and religious help and coping strategies were being adapted ${ }^{[18]}$. The assessment of well-being in 250 health care workers in one of the hospitals of a main city concluded that about $10-20 \%$ of health care workers developed symptoms during treating patients in corona wards, and they were quarantined. High levels of workload was found for the health care workers (9-10 hours), increasing the chances of depression. Statistically significant results were found between the PGWBI (psychological general well- being index) and corona phobia $(p=.000)$ ${ }^{[17]}$. The effects of pandemic on surgical procedures were notable. However, positive as well as negative outcomes on the surgical procedures were found in regard to the surgeons and surgical staff. About $86.6 \%$ complained that surgical procedures have been drastically affected due to this pandemic, $82.1 \%$ of the trainees responded that they have limited clinical exposure due to reduction in number of people in the operation theatre. Moreover, 615 were worried about transmission of the virus to them due to increased exposure, and $38 \%$ confirmed the deaths of their immediate family members by thus viral disease. However, the working hours of the surgical staff had been reduced because of this pandemic $^{[19]}$.

Though Coronavirus disease as well as ways to control it such as lockdown, social distancing cause psychological fear, anxiety, uncertainty and restlessness but research has shown that deaths apparently associated with COVID- 19 fear were actually due to financial issues during this pandemic. Twenty nine suicidal cases had been reported since January 2020, out of which 16 cases (with 12 suicidal deaths and four suicidal attempts) were found to be associated with COVID-19. Twelve males have economic issues due to this COVID-19, while only four suicidal deaths were reported because of fear of COVID-19 ${ }^{[12]}$. 


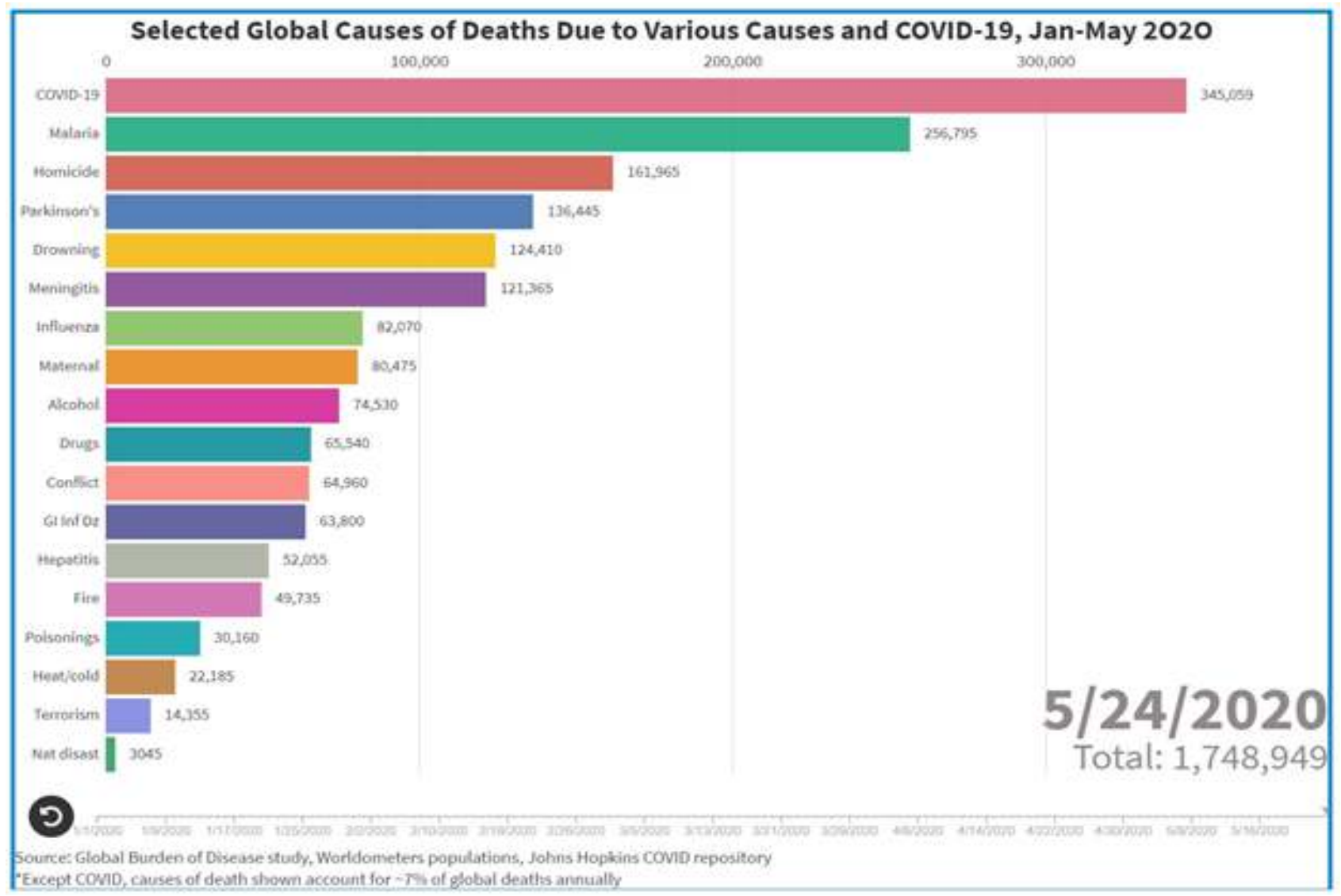

Figure-I: Global Causes of Death.

Available from URL: https://www.theweeklysource.com.au/watch-global-deaths-from-covid-19overtake-all-other-causes-of-death-in-2020/

Loss of healthy life years (in percentage of total DALY)

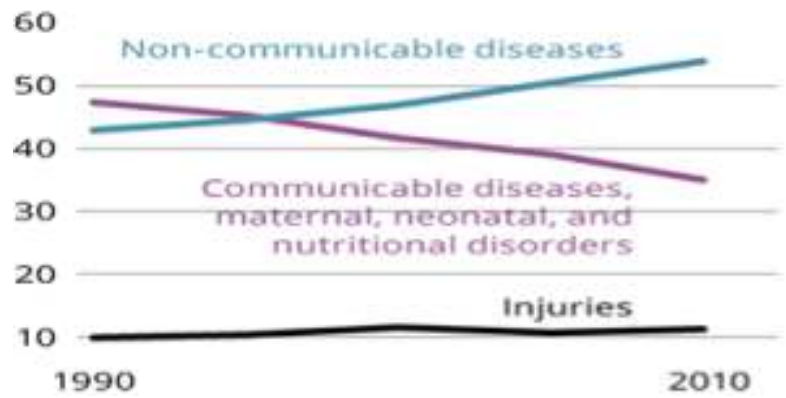
(Assessed on 3 June 2020)

Deaths related to non-communicable diseases (in percentage of total deaths)

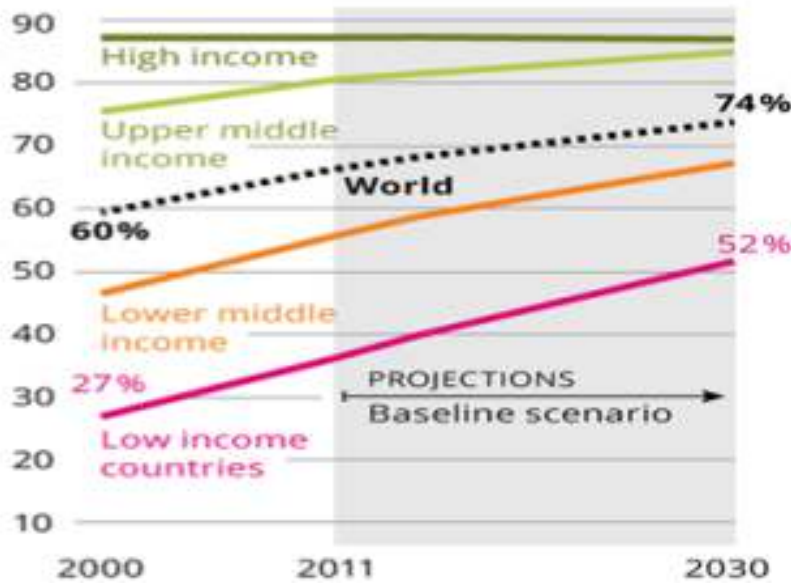

Figure-II: Predicted Shift of Disease Burden in South East Asia. Available from URL: https://www.eea.europa.eu/data-and-maps/figures/the-shift-in-global-disease (Assessed on 3 June 2020) 

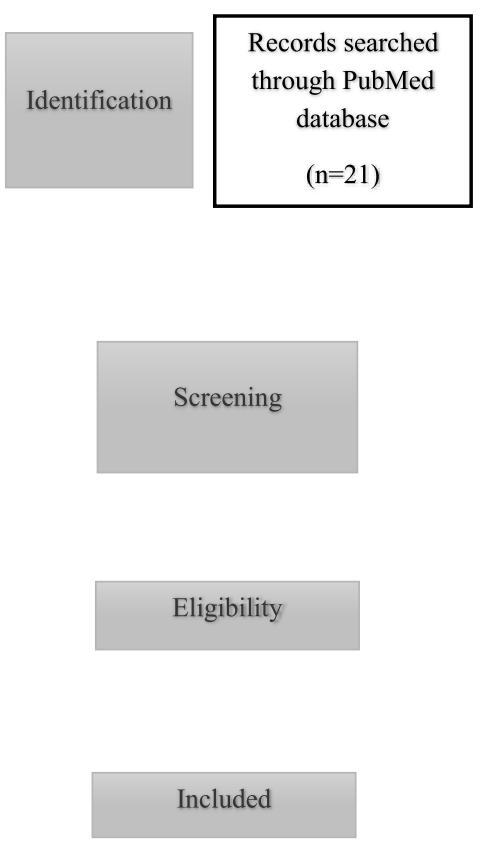
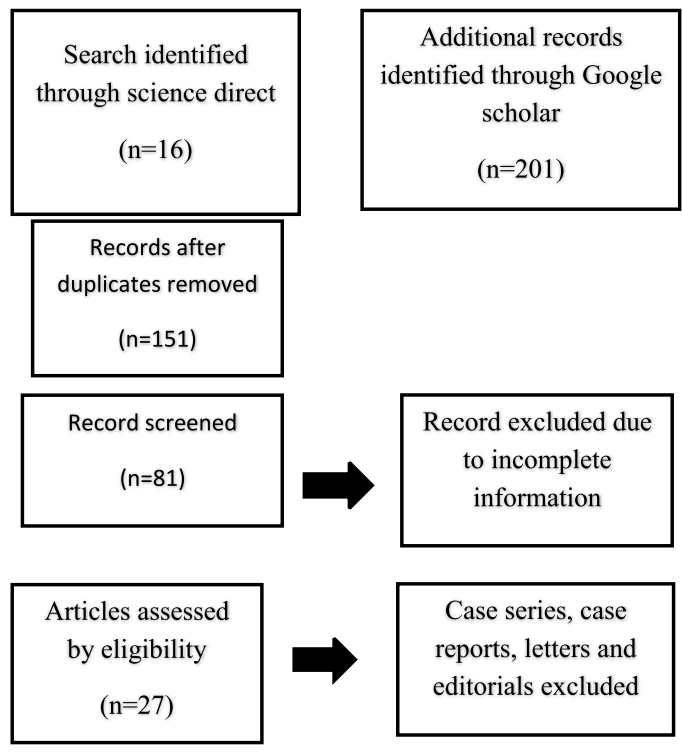

Studies included on inclusion criteria (case studies/cohort studies)

$(n=7)$

\section{Figure-III: PRISMA 2009 Flow Diagram showing study characteristics.}

\section{DISCUSSION:}

Up till June $30^{\text {th }}, 2020$ about 5.16 million individuals have recovered from coronavirus infection ${ }^{21}$. Their bodies are disease free now but what about their psychological status? Mental health has always considered as taboo and has a certain stigma attached to it, due to which nobody speaks up about it openly. It's about time that this issue should be highlighted and necessary interventions are introduced to make it better ${ }^{[7]}$.

In our systematic review, we observed COVID19 impact on mental health and found out that it has affected everyone but response varied differently. Younger lot has little knowledge of the disease and their response depend upon adults-their parents or guardians. Though they have milder symptoms and can be silent carriers of the virus, their screening is seldom focused ${ }^{[20,21]}$. Teenagers are active and energetic, so social isolation is hard for them as they want to do something different and challenging ${ }^{[14]}$. On the other hand, adults have responsibilities and they bear socioeconomic stresses. They understand the need of hour ${ }^{[22]}$.
Although elderly have lived major chunk of their lives but fear to die with coronavirus infection is much more in them, perhaps the stigma and restrictions on funeral ceremony might be the cause ${ }^{[23]}$. Our observations also coincides with the findings of Rodolfo Rossi and his colleagues who studied COVID-19 pandemic effects on Italian population during lockdown. The study population suffered post-traumatic symptoms, anxiety, depression and adjustment disorders. Women were more prone to these effects ${ }^{[6]}$.

Mental health issues affects the general population as well as those on the frontline. Health care workers are especially the ones most susceptible, due to the high pressure environment in which they work during pandemic. Although they are at higher risk, more prone to get infected but their sense of duty overpowers every obstacle. From senior consultants to junior paramedical staff, all work as a team. Despite of discouraging incidences, they stand strong ${ }^{[24]}$. Similar observations were recorded by Lijun Kang and his co-workers in their study regarding pandemic psychological 
effects on medical and nursing staff, working in Wuhan, China. Need of mental health interventions for healthcare workers and its positive impact was highlighted ${ }^{[25]}$.

Pakistan being a third world country, where there are lack of resources, such issues are inevitable, but there are many hindrances, factors that can prevent efficient reduction of mental health issues. These include lack of education, mistrust in authorities, development of conspiracy theories, there is a trend of avoiding important vaccination, avoiding seeking help whenever there is needed ${ }^{[11]}$. There are increased cases of domestic violence, general public is not trained to deal with this sudden traumatic events due to which there is great levels of vicarious traumatization. Also due to joint family system, social isolation has created a sense of uncertainty, helplessness, which has further aggravated the situation at hand ${ }^{[26]}$. Suicidal tendency is another devastating outcome due to decline in economic stability ${ }^{[27]}$.

COVID 19 is still under study but it is the need of the hour to deal with this secondary crisis of mental health issues just as vigorously. People should be encouraged to talk about themselves without the fear of being judged. Data should be compiled on mental health consequences and interventions introduced based on these figures.

\section{CONCLUSION:}

Although mental illnesses are already prevalent in Pakistan but they are potentiated by COVID-19 due to its multi-dimensional manifestations especially on the economic growth of the country. Health care professionals and those having previous history of any psychological issue are easy targets. Mental health problems might persist long after the pandemic is over, so preventive measures and disease management have to go hand in hand.

\section{LIMITATIONS:}

Few studies were included. Studies do not represent the whole population. Detailed demographical and ethnical information including socioeconomic status was not available.

\section{RECOMMENDATIONS:}

Mental health related issues might be overwhelming but population can be helped to deal with the ordeal.

- People should be encouraged to check on each other, to help adapt them to the new "normal'. Studies should be conducted to identify people at risk, to safeguard their interest.

- Mental health problems should be dealt at primary, secondary and tertiary level.

People should be encouraged to learn new skill, practice mindfulness, express gratitude, so there is no room left for negativity.

- Health care workers should be provided with an environment of support and protection, so that they can fight off this disease efficiently. Continuous counselling sessions and screening done at intervals to identify and work on such individuals.

- Other mediums should be put into practice to relieve some of the burden off from health workers shoulder. Online and electronic media can be utilized to educate communities and promote wellbeing of the society.

ACKNOWLEDGEMENT: None.

CONFLICT OF INTEREST: All authors disclose no conflict of interest.

\section{GRANT SUPPORT \& FINANCIAL DISCLOSURE: None.}

\section{REFERENCES:}

1. Jiang $F$, Deng $L$, Zhang L, Cai $Y$, Cheung CW, Xia Z. Review of the clinical characteristics of coronavirus disease 2019 (COVID-19). Journal of General Internal Medicine. 2020;35:1545-1549. Doi: $10.1007 / s 11606-020-05762-w$

2. Organization WH. Coronavirus disease 2019 (COVID-19): situation report, 72; 2020 [cited 2020 June 30]. Available at: https://www. who.int/emergencies/ diseases/novel-coronavirus-2019

JUMDC Vol. 12, Issue 1, January-March 2021 
3. Pappa S, Ntella V, Giannakas T, Giannakoulis VG, Papoutsi E, Katsaounou P. Prevalence of depression, anxiety, and insomnia among healthcare workers during the COVID-19 pandemic: A systematic review and meta-analysis. Brain, Behavior, andImmunity. 2020;88:901-907. Doi:10.1016/j.bbi. 2020.05.026

4. Singhal T. A review of coronavirus disease2019 (COVID-19). The Indian Journal of Pediatrics. 2020;87:281-286. Doi:10.1007/s12098-020-03263-6

5. Cullen W, Gulati G, Kelly B. Mental health in the Covid-19 pandemic. QJM: An International Journal of Medicine. 2020;113(5):311-312.

6. Rossi R, Socci V, Talevi D, Mensi S, Niolu C, Pacitti $F$, et al. COVID-19 pandemic and lockdown measures impact on mental health among the general population in Italy. Frontiers in Psychiatry. 2020;11:790.

7. Rüsch N, Angermeyer MC, Corrigan PW. Mental illness stigma: Concepts, consequences, and initiatives to reduce stigma. European Psychiatry. 2005;20(8):529-539. Doi:10.1016/ j.eurpsy.2005.04.004

8. Walker ER, McGee RE, Druss BG. Mortality in mental disorders and global disease burden implications: a systematic review and meta-analysis. JAMA Psychiatry. 2015;72(4):334-341. Doi: 10.1001/ jamapsychiatry.2014. 2502

9. Vigo D, Thornicroft G, Atun R. Estimating the true global burden of mental illness. The Lancet Psychiatry. 2016;3(2):171178. Doi: $10.1016 /$ S2215-0366(15) 00505-2

10. Hashmi AM, Saleem HA. New Horizons: COVID-19 and the Burden of Neuropsychiatric Illness in Pakistan. Pakistan Journal of Medical Sciences. 2020;36(COVID19-S4). Doi:10.12669/ pjms.36.COVID19-S4.2792

11. Saqlain M, Munir MM, Ahmed A, Tahir AH, Kamran S. Is Pakistan prepared to tackle the coronavirus epidemic? Drugs \& Therapy Perspectives. 2020;36:213-214. Doi: 10.1007/s40267-020-00721-1

12. Mamun MA, Ullah I. COVID-19 suicides in
Pakistan, dying off not COVID-19 fear but poverty? - The forthcoming economic challenges for a developing country. Brain Behaviour and Immunity. 2020;87:163166. Doi:10.1016/j.bbi.2020. 05.028

13. Goodell JW. COVID-19 and finance: Agendas for future research. Finance Research Letters. 2020:101512.

14. Imran N, Zeshan M, Pervaiz Z. Mental health considerations for children \& adolescents in COVID-19 Pandemic. Pakistan Journal of Medical Science. 2020;36(COVID19-S4):S67-S72. Doi: 10.12669/pjms.36.COVID19-S4.2759

15. Safdar M, Yasmin M. COVID-19: A threat to educated Muslim women's negotiated identity in Pakistan. Gender, Work \& Organization. 2020. Doi:10.1111/gwao. 12457

16. Aqeel M, Shuja KH, Abbas J, Rehna T, Ziapour $A$. The Inluence of Illness Perception, Anxiety and Depression Disorders on students Mental Health in Pakistan. 2020. Doi: 10.21203/rs.3.rs30128/v1

17. Amin S. The psychology of coronavirus fear: Are healthcare professionals suffering from corona-phobia? International Journal of Healthcare Management. 2020:1-8. Doi: $10.1080 / 20479700.2020 .1765119$

18. Salman M, Raza MH, Mustafa ZU, Khan TM, Asif N, Tahir $\mathrm{H}$, et al. The psychological effects of COVID-19 on frontline healthcare workers and how they are coping: a web-based, cross-sectional study from Pakistan. 2020. Doi: 10.1101/2020.06.03.20119867

19. Osama M, Zaheer F, Saeed $H$, Anees K, Jawed Q, Syed SH, et al. Impact of COVID19 on surgical residency programs in Pakistan; A residents' perspective. Do programs need formal restructuring to adjust with the "new normal"? A crosssectional survey study. international journal surgery. 2020;79: 252-256. Doi:10.1016/j.ijsu.2020.06. 004

20. Mustafa NM, Selim LA. Characterisation of COVID-19 Pandemic in Paediatric Age Group: A Systematic Review and MetaAnalysis. Journal of Clinical Virology. 2020;128:104395. Doi: 


\subsection{6/j.jcv.2020.104395}

21. Ludvigsson JF. Systematic review of COVID-19 in children shows milder cases and a better prognosis than adults. Acta Paediatrica. 2020;109(6):1088-1095. Doi: 10.1111/apa.15270

22. Lima CKT, Carvalho PMM, Lima I, Nunes J, Saraiva JS, de Souza RI, et al. The emotional impact of Coronavirus 2019nCoV (new Coronavirus disease). Psychiatry Research.2020;287:112915. Doi: 10.1016/j.psychres.2020.112915

23. Singhal T. A Review of Coronavirus Disease-2019 (COVID-19). Indian Journal of Pediatrics. 2020;87(4):281-286. Doi: 10.1007/s12098-020-03263-6

24. Montemurro N. The emotional impact of COVID-19: From medical staff to common people. Brain Behaviour and Immunity. 2020;87:23-24. Doi: 10.1016/j.bbi. 2020.03.032

25. Kang L, Ma S, Chen M, Yang J, Wang Y, Li R, et al. Impact on mental health and perceptions of psychological care among medical and nursing staff in Wuhan during the 2019 novel coronavirus disease outbreak: A cross-sectional study. Brain Behaviour and Immunity. 2020;87:11-17. Doi: $10.1016 /$ j.bbi.2020.03.028
26. Hashmi AM, Saleem HA. New Horizons: COVID-19 and the Burden of Neuropsychiatric Illness in Pakistan. Pakistan Journal of Medical Science. 2020;36(COVID19-S4):S95-S98. Doi: 10.12669/pjms.36.COVID19-S4.2792

27. Oyesanya M, Lopez-Morinigo J, Dutta R. Systematic review of suicide in economic recession. World Journal of Psychiatry. 2015;5(2):243-254. Doi:10.5498/wjp. v5.i2.243

\section{Author's Contribution:}

Seemi Tanvir: Idea concept, Study design, and Proof reading

Mariam Babar: Data collection, Data analysis, Manuscript writing.

Ayesha Fazal: Data Collection, Data analysis and Proof reading.

Faiqa Fazal: Final Review of manuscript.

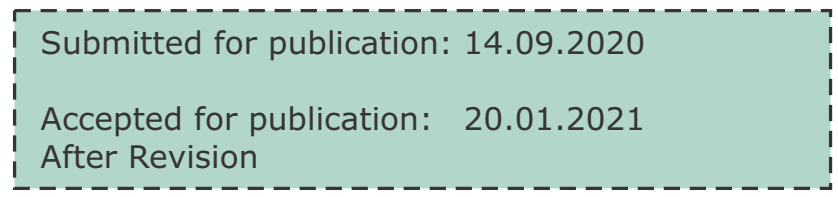

